\title{
A DANÇA NA EDUCAÇÃo FÍSICA ESCOLAR
}

\author{
Dr. Edson José Lira Turiano
}

\section{RESUMO}

Dançar é uma das maneiras mais divertidas e adequadas para ensinar, na prática, todo o potencial de expressão do corpo humano. Enquanto mexem o tronco, as pernas e os braços, os alunos aprendem sobre o desenvolvimento físico. Introduzir a dança na escola equivale a um tipo de alfabetização. "É um ótimo recurso para desenvolver uma linguagem diferente da fala e da escrita, aumentar a sociabilidade do grupo e quebrar a timidez". E o melhor: o trabalho pode ser feito com turmas de todas as idades e de forma interdisciplinar, envolvendo as aulas de Artes e de Educação Física.

Palavras-chaves: Dançar, aulas, Educação Física

\begin{abstract}
:
Dancing is one of the most fun ways to teach appropriate and in practice the full potential of expression of the human body. While stir the trunk, legs and arms, students learn about the physical. Enter the dance school amounted to a kind of literacy. "It's a great resource to develop a different language from speech and writing, increase the group sociability and break shyness." And the best work can be done with groups of all ages and an interdisciplinary approach, involving classes of Arts and Physical Education .
\end{abstract}

Keywords: dancing , lessons , Physical Education

\section{1 - INTRODUÇÃO}

Para despertar nos alunos o interesse pela dança, é preciso levar em consideração o repertório artístico que eles têm, deixar bem claro que homem também dança e, claro, convidar a turma toda para participar.

\footnotetext{
Muitas vezes vista como elitista, a dança é uma atividade de integração que se adapta muito bem a qualquer currículo. As fontes de inspiração para as aulas podem variar, de acordo com o projeto da escola e os interesses da turma o comportamento dos animais e os fenômenos da natureza, por exemplo, rendem boas atividades. A sala não precisa nem ter espelhos, como as dos grandes centros de dança: basta ser limpa, bem iluminada e ventilada. Para a aula ser produtiva e agradável, diga à garotada para usar roupas leves e confortáveis e tomar muita água, como em qualquer esporte, para não desidratar. (CAPRI, F.; FINCK, S., 2009, P.45)
}

É com estas palavras que iniciamos este trabalho com intuito de mostrar a importância da dança nas escolas interferindo na vida dos estudantes. 
Aulas monótonas, alunos sedentários, professores mecânicos e outras situações gritantes nãos são responsáveis pelo desinteresse de muitos alunos nas aulas de Educação Física? Não seria a dança um instrumento inovador para a atenuação no índice de sedentarismo de alguns estudantes como também fator inovador e motivador nas aulas de Educação Física?

"A Educação Física é uma disciplina obrigatória no currículo escolar, que têm tanta importância como qualquer outra disciplina obrigatória." (BRASIL, 1996).

Parâmetros foram elaborados para que fossem seguidos em todo o território brasileiro, para haver uma unificação na área da Educação Física, que é uma disciplina diretamente relacionada à corporeidade e seu bloco de conteúdos é: conhecimento sobre o corpo; esportes, jogos, lutas e ginásticas; atividades rítmicas e expressivas, esta última trata das danças e brincadeiras cantadas.

A dança é um conteúdo fundamental para ser tratado na escola. Uma das formas na prática mais adequadas e divertidas para ensinar todo o potencial de expressão do corpo. A dança, independentemente de sua modalidade, tem como objetivo buscar a expressão individual de pensamentos e sentimentos, desenvolvendo a psicomotricidade, que é uma percepção para gerar ações motoras que influenciam os fatores intelectuais, afetivos e culturais (MARTÍN et al., 2008). Sendo assim, o objetivo deste trabalho foi verificar, por meio de uma revisão sistemática da visão do conteúdo "dança” nas aulas de Educação Física.

Todos estes argumentos e muitos outros nos levaram a querer investigar um pouco sobre a importância da dança nas aulas de Educação Física.

\section{2 - METODOLOGIA}

Após levantamento bibliográfico fizemos algumas observações de algumas aulas de educação física na escola e em conversa informal com alguns professores percebemos que eles ministram sim a dança nas aulas de Educação Física, considerando ser um meio dinâmico para que os estudantes se interessem mais por este tipo de aula. E quanto aos alunos entrevistamos alguns a fim de sabermos qual a importância da dança nas aulas de educação física.

Escolhemos a pesquisa qualitativa, pois analisaremos como a dança acontece na escola lócus de pesquisa deste estudo.

Vamos conhecer um pouco sobre este tipo de abordagem, correlacionando-a com a quantitativa. 
Na escolha do tema do trabalho a ser desenvolvido, sabe-se que seu foco de estudo, seu objeto de análise, partirá, necessariamente, de um problema. Imaginemos que você decida compreender o fenômeno da falta de interesse dos alunos em relação a uma determinada disciplina. Obviamente que você terá de escolher qual será o método que utilizará para checar as causas envolvidas nessa problemática. Afirma-se, dessa forma, que, dependendo da abordagem do problema, a pesquisa pode se classificar como quantitativa ou qualitativa.

Continuemos, pois, aproveitando os exemplos práticos. Suponhamos que a intenção do pesquisador seja medir, quantificar, o grau de satisfação dos habitantes de uma determinada cidade no que se refere à administração do prefeito atual. Para tanto, ele teria de optar pela pesquisa quantitativa, haja vista que ela se traduz por tudo aquilo que pode ser quantificável, ou seja, ele iria traduzir em números as opiniões e informações para então obter a análise dos dados e, posteriormente, chegar a uma conclusão.

Partindo do princípio de que essa modalidade requer o uso de estatísticas e de recursos, como, por exemplo, percentagens, média, mediana, coeficiente de correlação, entre outros, como o objetivo é o de apurar as opiniões explícitas dos entrevistados, o questionário representa um dos meios mais eficazes para testar de forma precisa as hipóteses levantadas. Por meio de questões do tipo "fechadas", apresenta-se um conjunto de alternativas de respostas no intuito de se obter aquela que melhor representa o ponto de vista da pessoa entrevistada. Ao delinear de forma precisa e clara o que se deseja, tal procedimento garante uniformidade de entendimento por parte dos entrevistados, o que contribui para a eficácia, a precisão e a padronização dos resultados.

\section{3 - DESENVOLVIMENTO}

\section{1 - A dança e seus conceitos}

"Dança é a arte de movimentar expressivamente o corpo seguindo movimentos ritmados, em geral ao som de música”.

O povo primitivo iniciou a arte de dançar e a praticava em diferentes ocasiões: no período de colheitas, nos rituais aos deuses, na época das caçadas, nos casamentos, em momentos de alegria ou tristeza, ou ainda, em homenagem à mãe natureza. É considerada a mais completa das artes, pois envolve elementos artísticos como a música, o teatro, a pintura e a escultura, sendo capaz de exprimir tanto as mais simples quanto as mais fortes emoções.

Segundo Carbodera, 2009 o significado da dança vai além da expressão artística, 
podendo ser vista como um meio para adquirir conhecimentos, como opção de lazer, fonte de prazer, desenvolvimento da criatividade e importante forma de comunicação. Através da dança, uma pessoa pode expressar o seu estado de espírito. A dança pode ser acompanhada por instrumentos de percussão ou melódicos, ou ainda pela leitura de diferentes textos.

A dança teve forte influência nas sociedades ao longo dos tempos. Como via de socialização e disseminação de cultura, proporcionou ao mundo o conhecimento sobre a diversidade cultural dos diferentes povos em todo mundo, especialmente através das danças folclóricas.

\section{2 - A dança e seus benefícios na boa qualidade de vida}

Os benefícios da dança como uma atividade física são bem conhecidos: flexibilidade, melhora do condicionamento aeróbico, aprimoramento da coordenação motora e perda de peso, entre tantos outros. Mas pouco se fala da dança como uma terapia para a alma. Basta observar com um pouco mais de atenção para perceber que os resultados vão muito além do bem-estar físico.

“Algumas pessoas dançaram a vida inteira, outras só descobriram esse prazer depois da aposentadoria ou após encaminhar os filhos na vida. E depois que eles começam, não querem mais parar". Representantes da Melhor Idade comparecem com um único compromisso: se divertir. Basta observar durante poucos minutos e já é possível perceber a alegria de cada um ao estar ali, dançando. O professor da Cia Jundiaiense de Dança explica que a dança de salão é indicada muitas vezes para quem faz terapia de casal. "Isso porque eles se tornam mais próximos e acabam resgatando toda a cumplicidade do início do relacionamento.

\section{3 - Concepções gerais sobre a dança nas aulas de educação física}

O instrumento principal de construção de uma experiência lúdica é o corpo, e a dança pode levar à coordenação estética dos movimentos corporais pela manifestação motora, expressiva, representativa que segue determinado ritmo, nas diversas maneiras de sentir, pensar e atuar.

A dança trás inúmeros benefícios sociais, culturais, emocionais, cognitivos e motores de maneira conceitual, atitudinal e procedimental que favorecem a conscientização do corpo e do senso crítico, formando um cidadão autônomo, ciente de seus direitos e deveres. 
Evidenciou-se, por meio de investigação de revisão bibliográfica, que a dança é considerada pelos profissionais e estudantes de Educação Física muito importante no meio educativo, porém constatou-se que a maioria dos entrevistados tem dificuldade em aplicá-la em razão de preconceitos, deficiência na formação da graduação, ausência de infra estrutura escolar, por não estar no planejamento curricular da sua escola ou por falta de afinidade com ela.

A dança é um meio que a Educação Física tem que se caracteriza por ser uma prática que preconiza o movimento e este requer elementos com ritmo, expressão e forma. Os elementos trabalhados na dança por meio da música criam experiências que auxiliam na elaboração do pensamento, implicando uma consciência rítmica, recepção auditiva, compreensão intelectual da música, levando a um desenvolvimento maior que apenas as faculdades corporais e mentais, contribuindo para o desenvolvimento integral da personalidade em todos os âmbitos.

\footnotetext{
Contudo, os futuros profissionais e profissionais de Educação Física devem refletir, pois os alunos não podem ser prejudicados aprendendo apenas aquilo com o que seus professores têm mais afinidade, aprendendo os mesmos conteúdos em todos os anos escolares, e sim explorar o máximo de vivências corporais possíveis, pois tudo se torna um desafio. PACHECO, A. J. P. 1998/1999, P. 89)
}

Espera-se que este trabalho contribua para que os profissionais de Educação Física possam refletir e discutir o conteúdo da dança em suas aulas. Sugerimos estudos mais aprofundados a respeito dos benefícios da dança nas aulas de Educação Física e que possam ajudar o professor a aplicar o conteúdo da dança em sua aulas de maneira criativa, ampla e diversificada.

\section{4 - CONCLUSÃO}

Ao final deste estudo pudemos notar que a escola tenta inserir a dança como um instrumento de melhoria na aprendizagem e no condicionamento físico e mental dos estudantes. Os estudantes precisam desmistificar alguns conceitos sobre dança que são ultrapassados e mesquinhos. Após as leituras que fizemos entendemos a dança como uma possibilidade de expressão que deve ser considerada uma aliada no desenvolvimento de um amplo repertório das potencialidades humanas, devido a seus métodos criativos e expressivos. E também, por ser cultura de movimento que demarca manifestações culturais de comunidades e povos, servindo como um meio de comunicação através do movimento.

É impossível não considerar sua presença na atualidade e no contexto escolar, 
fazendo-se presente como conteúdo da Educação Física. Por sua vez, encontram-se muitas dificuldades de aceitação para a sua aplicação prática; dificuldades estas culturais, como por exemplo, preconceito e influência da mídia.

A dança promove uma relação que se processa entre os corpos contribuindo para a socialização do indivíduo, servindo como um instrumento para potencializar na criança a compreensão da sua capacidade de movimento, conseguindo ter um entendimento maior de como funciona seu corpo, desenvolvendo suas emoções, expressões, criatividade fazendo com que se comunique melhor no meio social.

A nova visão da dança, em seu aspecto cultural, é um conteúdo indispensável na escola, pois sua contribuição é favorecer a formação da cidadania, tornando nossos alunos cidadãos críticos sensíveis e conscientes de suas ações na sociedade.

Resultados obtidos em entrevista com alunos sobre a importância da dança nas aulas de Educação Física.

1. Entre todos os entrevistados, a dança é considerada um conteúdo da Educação Física escolar.

2. A maioria dos alunos se imagina aprendendo dança na escola, mas apenas o básico e, ainda, o relata com certa insegurança.

3. As maiores dificuldades para a inserção da dança na escola são a escassez de vivência, a falta de preparo que possuem no trato com o conteúdo, bem como o preconceito de alunos, pais, professores.

4. Parece haver concepção hegemônica do esporte em detrimento da dança. Alunos gostam muito mais do futebol, por exemplo, do que a dança.

Resultados obtidos em entrevista com professores sobre a importância da dança nas aulas de Educação Física.

1 - O preparo para ensinar dança não vem da graduação, mas de vivências anteriores e/ou fora da faculdade, bem como seu ensino na escola está sujeito ao interesse e afinidade do próprio professor com tal conteúdo.

2 - Gostariam de capacitação especifica para este tipo de atividades. Alguns professores não sabem dançar.

3 - Todos os professores observados e entrevistados por nós, mostraram interessem em se aprofundar na atividade da dança.

\section{REFERÊNCIAS BIBLIOGRÁFICAS}


AGOSTINI, B.; PALOMARES, E. Dança Educação no meio universitário: expectativas e necessidades. Revista Brasileira de Educação Física, Esporte, Lazer e Dança (REFELD), v. 3, n. 3, p. 61-68, 2008.

BARRETO, Débora. Dança... Ensino, Sentido e Possibilidades na Escola, 163 págs., Ed. Autores Associados.

BERNARDINO, E. J. et al. A dança no contexto da educação física: na visão de professores de ensino infantil e fundamental de Romaria-MG. 2009.

BERTAZZO, Ivaldo. Espaço e Corpo Guia de Reeducação do Movimento 235 págs., Ed. SESC SP.

BETTI, I. Esporte na escola: mas é só isso professor? Revista Motriz, v. 1, n. 1, p. 25-31, 1999.

BETTI, M. Corpo, cultura, mídias e Educação Física: novas relações do mundo contemporâneo. Revista Digital EFDesportes.com, Buenos Aires, v. 10, n. 79, 2004.

BRASIL. Lei Federal n. 9.394/1996 - Lei de Diretrizes e Bases da Educação Nacional, 1996.

BRASIL. Secretaria de Ensino Fundamental. Parâmetros Curriculares Nacionais $3^{\circ} \mathrm{e} 4^{\circ}$ ciclos do Ensino Fundamental: Educação Física. Brasília: MEC/SEF, 1998.

BRASILEIRO, L.; MARCASSA, L. Linguagem do corpo: dimensões expressivas e possibilidades educativas da ginástica e da dança. Revista Pro-Posições, v. 19, n. 3, p. 57, 2008.

CAPRI, F.; FINCK, S. A dança na visão de professores de Educação Física das escolas de Ponta Grossa-PR. Congresso Nacional de Educação - EDUCERE, 9., 2009, III Encontro Sul Brasileiro de Pisicopedagogia - PUCPR, 2009.

CARBONERA, D.; CARBONERA, S. A importância da dança no contexto escolar. Cascavel: ESAP, 2008.

CASTRO, P. L.; AUBERO, A. E. El movimiento y la danza: su importancia dentro del curriculum de primaria. Educación y Futuro, n. 17, p. 149-163, 2007.

CIGARAN, S. R. Danza movimiento terapia: cuerpo, psique y terapia. Avances en Salud Mental Relacional, v. 8, n. 2, p. 1-20, jul. 2009. 
COLETIVO DE AUTORES. Metodologia do ensino de Educação Física. São Paulo: Cortez, 1993.

DUARTE, R. Pesquisa qualitativa: reflexões sobre o trabalho de campo. Caderno de Pesquisa, n. 115, p. 139-154, março/2002.

GIL, A. C. Como elaborar projetos de pesquisa. 4. ed. São Paulo: Atlas, 2002.

Métodos e técnicas de pesquisa social. 5. ed. São Paulo: Atlas, 1999.

MARCONI, M. de A.; LAKATOS, E. M. Fundamentos de metodologia científica. 5. ed. São Paulo: Atlas, 2003.

PACHECO, A. J. P. Educação física e dança: uma análise bibliográfica. Pensar a Prática, v. 2, p. 156$171,1998 / 1999$.

RUDIO, F. V. Introdução ao projeto de pesquisa científica. Petrópolis: Vozes, 1986.

SANTOS, J. T.; LUCAREVSKI, J. A.; SILVA, R. M. Dança na escola: benefícios e contribuições na fase pré-escolar, 2005,

SANTOS, R. C.; FIGUEIREDO, V. M. Dança e inclusão no contexto escolar, um diálogo possível. Pensar a Prática, v. 6, p. 107-116, 2002/2003.

SARAIVA, M. C.; FIAMONCINI, L. Dança na escola: a criação e a co-educação em pauta. In: KUNZ, E. (org). Didática da Educação Física. 4. ed. Unijuí-SP: Unijuí, 2006.

SILVA, M. G. M. S.; SCHAWARTZ, G. M. A expressividade na dança: visão do profissional. Revista Motriz, v. 5, n. 2, p. 168/177, 1999.

SOUZA, M. I. G. Arte, cultura e sociedade: uma rede intrigante para algumas reflexões sobre a dança. 2007. Disponível em: http://www.lazer.eefd.ufrj.br/producoes/ines_enfefe_2004.pdf.. Acesso em: 5 junho, 2007.

STRAZZACAPPA, M. A Educação e a fabrica de corpos: a dança na escola. Cadernos Cedes, ano XXI, n.53, 2001. 
Dança na Educação discutindo questões básicas e polêmicas. Pensar a Prática, v.6, p. 73-85, 2002/2003.

VERDERI, E. B. L. P. Dança na escola. Rio de janeiro: Sprint, 1998. 